\title{
Lugar e espacialidade: contribuições para uma hermenêutica topológica*
}

\section{Place and spaciality: contributions to topological hermeneutics}

DOI:10.12957/ek.2017.30219

\author{
Prof ${ }^{\mathrm{a}}$.Dr ${ }^{\mathrm{a}}$. Rebeca Furtado de Melo \\ rebecafurtado7@gmail.com \\ Colégio Pedro II - Campus Tijuca II
}

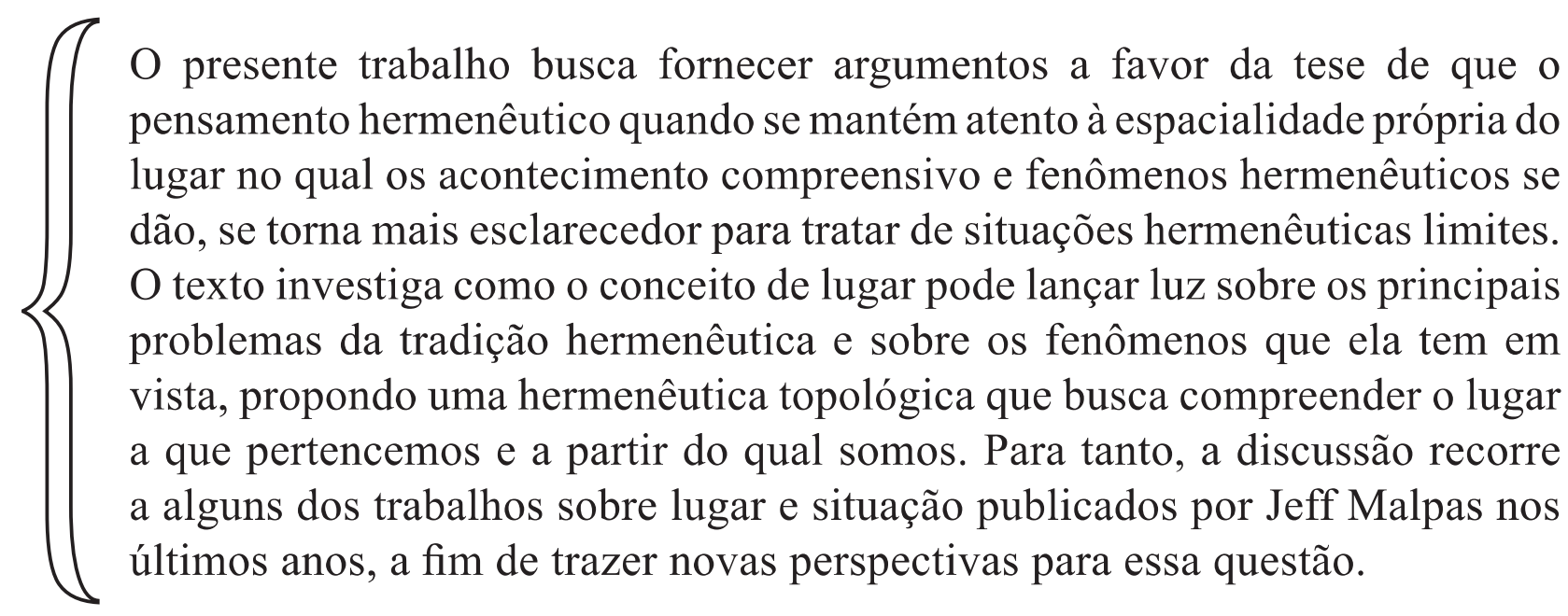

PALAVRAS-CHAVE Lugar. Espacialidade. Hermenêutica topológica

This work aims to give some arguments to defend the thesis that hermeneutical thinking becomes stronger when it takes in consideration the spaciality of place within the comprehensive event and hermeneutical phenomenon happening and so, it can describe the boundary hermeneutical situations. This paper investigates how the concept of place helps us to think about the main problems of hermeneutical tradition, proposing a topological hermeneutics to understand the place where we belong to and from where we are. For that, the discussion brings some Jeff Malpas's papers and its perspectives and contributions to this question.

KEYWORDS Place. Spaciality. Topological hermeneutics. 


\section{Introdução}

A primazia da temporalidade em detrimento da espacialidade, tal como foi levada a cabo nas compreensões teóricas da tradição hermenêutica, não corresponde a uma descrição ou a uma característica absoluta do fenômeno compreensivo ou de dação das coisas. Isto não quer dizer que a temporalidade seja um fator dispensável ou menos importante no acontecimento dos horizontes hermenêuticos, mas, ao contrário, aponta para o fato de que a retomada do inegável, ainda que bastante negligenciado, caráter espacial da hermenêutica pode nos ajudar a descrever melhor o que está em jogo no fenômeno de abertura de sentido no interior da qual existimos e nos relacionamos com as coisas e com os outros. Daí surge a centralidade do conceito de lugar como uma noção capaz de abarcar tanto os aspectos temporais quanto os traços espaciais do acontecimento desta abertura. Como se sabe, a palavra topologia possui como radical a palavra grega topos, comumente traduzida por lugar. Desta maneira, o pensamento hermenêutico se depara com a tarefa de resgatar a estrutura topológica da compreensão em estas duas dimensões (MALPAS, 2015b, p. 16), e é neste sentido que se propõe aqui uma hermenêutica topológica. Visando avançar nesta empreitada, necessitamos discutir melhor em que consiste tal espacialidade e em que medida ela enriquece o pensamento hermenêutico, apontando em seguida, elementos para se pensar e desenvolver uma hermenêutica topológica.

\section{A espacialidade dos conceitos hermenêuticos e a tradição hermenêutica}

Não é difícil encontrar nos conceitos hermenêuticos certa referência espacial. Podemos encontrá-la, por exemplo, na noção de horizonte de sentido, em termos centrais como interpretação ou compreensão, bem como na expressão 'círculo hermenêutico': todas essas palavras trazem consigo, em maior ou menor medida, uma noção de espacialidade. Aqui se pretende discutir o caráter e relevância de tal espacialidade para o pensamento hermenêutico a fim de questionar até que ponto resgatá-la atentamente nos ajuda a compreender melhor os fenômenos e problemas hermenêuticos.

Comecemos com a expressão ‘círculo hermenêutico' uma vez que ela desempenhou um papel central nesta tradição. Tal expressão, empregada pela primeira vez por Friedrich Ast em 1806 (MALPAS, 2015a, p.3), foi assimilada 
por boa parte dos autores da assim chamada tradição hermenêutica, tais como Schleiermacher, Dilthey, Heidegger e Gadamer. Por esta razão, podemos afirmar que encontramos a noção de 'círculo hermenêutico' desde quando a hermenêutica ainda era tomada como 'arte da interpretação do discurso alheio' até a proposta contemporânea de uma hermenêutica filosófica, consolidada por Gadamer no século XX. Ainda que em cada um desses autores a expressão ganhe um significado e papel específico no interior de suas obras e projetos, o que está em jogo aí é certa circularidade essencial e insuperável na relação compreensiva entre o todo e suas partes. Quer dizer: os processos interpretativos se dão de maneira circular. A circularidade diz respeito à vinculação do significado das partes ao todo, da mesma maneira que o sentido do todo se define por meio do significado das partes. Essa codeterminação originária não conhece um ponto de partida linear e ao mesmo tempo se fecha sobre si mesmo. A circularidade que vincula todo significado e sua compreensibilidade a um sentido não é uma espécie de metáfora espacial extraída de outro âmbito, como se fosse possível transportar conceitos geométricos ao pensamento hermenêutico. Mas, ao contrário, expressa propriamente a relação existente entre as partes e o todo nos processos interpretativos, em sua vinculação insuperável e de codependência.

A circularidade põe em evidência certa qualidade própria à abertura do espaço compreensivo no qual toda interpretação se realiza. O termo descreve as características do lugar da interpretação, isto é, descreve a maneira como se constituem os limites no interior do qual uma interpretação se torna possível. A noção de horizonte de sentido aparece aí como uma expressão correlata da noção de círculo hermenêutico, pois aponta, da mesma forma, para a delimitação do lugar no interior do qual algo pode aparecer e conquistar sua consistência própria. O horizonte delimita qualitativamente o lugar de mostração e presentação de algo. Isso quer dizer que ele determina os limites no interior dos quais algo aparece como tal, quer se trate de uma palavra, da frase de um texto ou de um ente no mundo. Esse limite precisa ser entendido como o que permite que a coisa se mostre como o que é, quer dizer, como aquilo que determina o campo de visibilidade e determinação de algo. Limite, interior, lugar: todos são conceitos topológicos que guardam certa espacialidade própria.

Mesmo os termos compreensão e interpretação, conceitos chave para a tradição hermenêutica, trazem em sua etimologia claras referências espaciais. Compreensão aponta para o ato de capturar completamente o que sucede ou foi dito - o termo pressupõe, assim, uma tensão entre distância e proximidade, uma relação espacial, uma vez que, implicitamente, declara que precisamos nos aproximar ao que buscamos entender para sermos capazes de "agarrá-lo". Por 
sua vez, o prefixo 'inter' da palavra interpretação pressupõe o estar “entre", no meio do que se busca intermediar, revelando igualmente referências espaciais. Também o prefixo trans, que compõe o termo tradução, ressalta o ato de guiar o translado, isto é, ir de um lado ao outro, mudar de lugar - neste caso, a mudança se dá do idioma de origem ao idioma de chegada.

Ressaltamos os aspectos espaciais e topológicos dos principais conceitos hermenêuticos. Ainda que esta não seja uma lista exaustiva, parece suficiente para chamar atenção para tal característica inegável. Além disso, podemos encontrar evidências textuais de que os próprios autores desta tradição estavam cientes da espacialidade característica do pensamento hermenêutico e o abordaram em maior ou menor medida. Há, por exemplo, uma consideração textual de Dilthey do caráter espacial do espírito objetivo quando ele diz: "Pois a obra de um gênio representa uma comunhão de ideias e de vida anímica, o compartilhamento de um ideal em uma época e em uma região.”. (DILTHEY, 2010, p. 189, grifo nosso). O espírito objetivo, portanto, expresso pela obra do gênio, não pode ser reduzido à concreção de um horizonte de sentido epocal, que resguarde somente características temporais. Ao contrário, é ao mesmo tempo espacial e topológico por ser a concreção de uma "comunhão de ideais e de vida" em uma região. Contudo, em Dilthey, as referências a este aspecto são escassas quando comparadas a temas e termos que destacam os aspectos temporais tais como: a ideia de época, de história e de conceitos correlatos. $\mathrm{O}$ mesmo ocorre em quase todos os pensadores desta tradição. A discussão sobre a espacialidade quase nunca é coloca em primeiro plano e em algumas ocasiões é apenas insinuada.

Além disso, parece que a tradição hermenêutica em geral é perpassada pela ideia de que existe uma espécie de continuação histórica (ainda quando inclui rupturas epocais) que se realiza através de uma tensão entre presente, passado e futuro, que forma e constitui a tradição e os horizontes de sentido epocais ${ }^{1}$. Neste sentido, a hermenêutica parece se comprometer com a tese de que existe certa primazia da temporalidade em detrimento da espacialidade, na qual a última é considerada como um aspecto de segunda ordem ou como uma noção derivada, se comparada à primeira. Contudo, o acento exagerado na temporalidade ou a desconsideração da espacialidade da hermenêutica traz algumas limitações para o pensamento, na medida em que tal concepção restritamente temporal não dá conta de pensarmos os fenômenos hermenêuticos em sua máxima abrangên-

1 De maneira evidente, podemos encontrar essa ideia, ainda que com desdobramentos muito distintos, em Dilthey e o espírito objetivo de um tempo, na história do ser heideggeriana, na história efeitual gadameriana, e, ainda, nas concepções de apropriação interpretativa da tradição nietzschiana em suas famosas considerações sobre a utilidade da história para a vida (Segunda Intempestiva). 

contribuições para uma hermenêutica topológica
Prof.- Drª . Rebeca

Furtado de Melo

[CP II - RI]

cia, nem nos permite questionar situações compreensivo-interpretativas específicas ${ }^{2}$, além de ter implicações ético e políticas que precisam ser consideradas. Esse empobrecimento se dá em todas os "níveis" hermenêuticos desde a tarefa de interpretar textos até o questionamento sobre a compreensibilidade dos entes, ou sobre a nossa maneira de existir no mundo. Poderia enumerar, por exemplo, os seguintes problemas devenientes desse abandono ou desconsideração da espacialidade na hermenêutica:

a) A falta de atenção à regionalidade hermenêutica no tocante à interpretação de textos desconsidera a possibilidade de que alguns termos no interior da obra de um autor podem ter uma pluralidade semântica não apenas em diferentes momentos de sua obra, mas, igualmente, em diferentes lugares contemporâneos desta obra. Se pensarmos, por exemplo, em um autor que escreve em aforismo como Nietzsche, esse problema se mostra de maneira mais evidente. Determinados conceitos ou palavras assumem diferentes significações dependendo do lugar em que eles aparecem, isto é, da totalidade relacional a que eles pertencem. Nesse sentido, aforismos podem funcionar como lugares autônomos, em maior ou menor medida, na determinação do significado e do uso que as palavras recebem em uma totalidade regional. Isso também pode ser pensado em relação a autores que escrevem obras mais linearmente argumentativas. Poderíamos citar o uso heideggeriano dos termos Situation e Lage em Ser e tempo, por exemplo. No primeiro momento, um termo aparece como aposto explicativo para o outro e,

\footnotetext{
2 Essa é em grande medida uma das teses centrais de Günter Figal em seu livro "Oposicionalidade: o elemento hermenêutico e a filosofia" (Gegenständlichkeit: Das Hermeneutische und die Philosophie), que representa uma clara exceção na tradição hermenêutica por resgatar tal espacialidade dos fenômenos hermenêuticos. Aí Figal dedica especialmente o parágrafo $§ 15$ denominado "Espaço", para discutir o aspecto espacial inquestionável da hermenêutica. Ele afirma, por exemplo: "Onde há espaço, temos abertura, há travessia e vizualização, o som se expande; no espaço há afastamento e amplitude, no espaço há distanciamento. Tudo isso poderia ser um sinal de que temos de pensar espacialmente a abertura daquilo que se apresenta. Neste caso, mesmo a correlação na qual algo aparece para alguém seria espacial; a compreensão do espaço seria a chave para a compreensão da fenomenalidade." (FIGAL, 2007, 159). A espacialidade que quero resgatar aqui é justamente esta que sempre se instaura junto com a fenomenalidade dos entes e que precisa ser considerada quando pensamos qualquer possibilidade de interpretá-los, quer teórica, quer existencialmente.

3 Para uma discussão mais detida sobre a diferença conceitual entre os dois termos em Ser e tempo, ver: SCHEAR. "Historical finitude" In: Wrathall, Mark (ed.). The Cambridge Companion to Heidegger's Being and Time. Cambridge: Cambridge University press, 2013; ou ainda, mais tangencialmente, DREYFUS, "Can there be a better source of meaning than everyday practices?" (especialmente pág. 146 em diante) In: Polt, Richard (ed). Heidegger's Being and time: Critical essays. Oxford: Rowman \& littlefield publiushers, 2005; e EVENS. "Some ontological implications of situational analysis". In: The Manchester School: Practice and Ethnographic Praxis in Anthropology. Oxford: Berghanbooks, 2006, especialmente, parte IV em diante.
} 

[CP II-R]]

neste sentido, são tomados praticamente como sinônimos (ST, §60, p. 89), mas, logo em seguida, os termos são usados para explicitar duas condições possíveis (e contrárias) em relação à situabilidade inerente ao ser-aí, uma relação autêntica e outra inautêntica (Idem, p. 90). Aí Heidegger afirma que a situação (Situation) permanece velada para o impessoal, que conhece apenas situações gerais ["allgemeine Lage"], (ou casos gerais, como aparece na tradução corrente brasileira). Independente da concordância ou não com os exemplos acima, o fato, difícil de ser negado, é que os mesmos termos e conceitos podem aparecer de maneira diversa em diferentes contextos (lugares) nas obras dos filósofos ou autores em geral em um mesmo período temporal, e seria muito redutor não levar em conta tais empregos regionais na tarefa de interpretação textual, sendo ela de cunho filosófico ou não.

b) Não atentar para a espacialidade própria dos fenômenos hermenêuticos pode levar a uma generalização exacerbada dos acontecimentos hermenêuticos em descrições que privilegiam totalidades epocais. Assim, pensando a partir de Dilthey ou mesmo da história do ser no segundo Heidegger, corremos o risco de desconsiderar a pluralidade de regiões que podem coexistir em um determinado tempo, ou mesmo fenômenos que se articulam com o horizonte hegemônico, mas que não podem ser reduzidos a ele, sem desconsiderarmos sua especificidade e, portanto, subestimar ou ignorar sua alteridade. Tal desconsideração da espacialidade tende a homogeneizar fenômenos irredutíveis em sua singularidade a um único nexo ou palavra fundamental do ser. Essa é uma crítica bastante comum a Heidegger, sobretudo, quando se comenta a muito conhecida e problemática passagem, na qual ele equipara fenômenos que parecem ser tão ontologicamente distintos como industrialização da agricultura e a "produção de corpos" nos campos de concentração e extermínio nazistas ${ }^{4}$, como duas manifestações equivalentes do mundo da técnica. Ainda que se possa encontrar ressonância entre os fenômenos, é difícil aceitar que um pode ser simplesmente e "essencialmente" reduzido ao outro quando pensados a partir da palavra fundamental do mundo da técnica.

4 "Agriculture is now a mechanized food industry, in essence the same as the production of corpses in the gas chambers and extermination camps, the same as the blockading and starving of countries, the same as the production of hydrogen bombs." (HEIDEGGER, 2012, p. 27) 
c) Abordagens hermenêuticas com preeminência temporal costumam desenvolver noções de história demasiadamente eurocêntricas e, possivelmente, colonialistas e/ou racistas. Se, por um lado, temos que conceder que a narrativa hegemônica da história da filosofia foi ligada à história do Ocidente, especialmente à Europa, e, ainda, reconhecer que é compreensível que pensadores europeus estejam engajados política e existencialmente com os desdobramentos históricos e com problemas filosóficos que emergem do modo de vida europeu, por outro lado, é inegável que, por vezes, esse engajamento se transforma em uma justificativa e defesa teórica de uma pseudo-relação essencial entre pensamento (e/ou filosofar e/ou história) e Europa ${ }^{5}$. A ideia de se pensar uma tradição como um acontecimento histórico que se desdobra articulando o presente, o passado e o futuro, conjugada com a noção de que o filosofar é (ou articula) as capacidades mais elevadas do ser humano e/ou ainda com a crença que apenas na Europa tal tipo de pensamento se tornou possível, dá margem a afirmações colonialistas e racistas, que foram usadas em grande medida nos processos coloniais a partir do argumento "civilizatório". Além dos evidentes impasses éticos e políticos desta posição, considerando que tais argumentos embasaram os genocídios e saqueios colonialistas ao redor do mundo, essas teses são questionáveis e problemáticas em relação à sua consistência filosófica já que não existe qualquer argumento legitimo para afirmar tal superioridade ou exclusividade da Europa como único lugar do pensamento e que o eurocentrismo aparece, geralmente, como um dogma inquestionável, quer dizer, como um mito fundador dessa pseudo superioridade.

Por isso, resgatar a espacialidade própria dos fenômenos hermenêuticos pode colaborar para que não caiamos em certo empobrecimento ou teses questionáveis em relação aos fenômenos em questão. Mas como, afinal, isto pode ser feito?

5 Não faltam exemplos de afirmações eurocêntricas entre filósofos ocidentais e, na maioria das vezes, essas afirmações se articulam a partir de algum argumento a favor da historicidade própria do Ocidente. Para alguns exemplos, conferir: "Eurocentrismo e racismo nos clássicos da filosofia e das ciências sociais" de Walter Praxedes. In: Revista Espaço Acadêmico, n 83, abril de 2008. Ver também, sobre o contexto específico da filosofia heideggeriana, o artigo de Sonia Sikka (2003), referência completa ao final do artigo.

6 Para uma discussão específica sobre a defesa dos processos colonialistas como missões civilizatórias e da negação da história aos povos não europeus como fundamento da subalternização ontológica e epistemológica dos mesmos, ver os textos de Maria Paula Menezes nas referências bibliográficas, ao final do artigo. 


\section{Horizonte, limites e lugar}

Em Verdade e Método, Gadamer fornece una longa discussão sobre a mobilidade própria de todo horizonte, mostrando como, desta maneira, um horizonte nunca pode ser pensado como algo insuperável ou fechado em si mesmo. Esta discussão que culmina na formulação da noção de 'fusão de horizontes' é paradigmática para explicitar e compreender a espacialidade própria da hermenêutica. Aí Gadamer diz:

Todo presente finito tem seus limites. Nós determinamos o conceito da situação justamente pelo fato de que representa uma posição que limita as possibilidades de ver. Ao conceito da situação pertence essencialmente, então, o conceito do horizonte. Horizonte é o âmbito de visão que abarca e encerra tudo o que é visível a partir de um determinado ponto. (...) A mobilidade histórica da existência humana apoia-se precisamente em que não há uma vinculação absoluta a uma determinada posição, e nesse sentido tampouco existe um horizonte fechado. $\mathrm{O}$ horizonte é, antes, algo no qual trilhamos o nosso caminho e que conosco faz o caminho. Os horizontes se deslocam ao passo de quem se move. Também o horizonte do passado, do qual vive toda vida humana e que está aí sob la forma da tradição, põe em movimento o horizonte abrangente. (GADAMER, 1999, p. 452 e 455).

Toda essa passagem usa conceitos espaciais e topológicos como: limite, posição, horizonte, movimento. O mais importante aí é que se esclarece como a noção de horizonte hermenêutico diz respeito ao pertencimento a uma posição, que permite ver o que vemos. A espacialidade própria da hermenêutica, portanto, não deve ser pensada como uma simples posição objetiva determinável matematicamente em um espaço entendido como extensão absoluta, o que Jeff Malpas denominou "espacialidade objetiva" (MALPAS, 2008, p. 72)7. Ao contrário, ela aponta para uma abertura dos limites no interior do qual existimos e podemos compreender as coisas, a nós mesmos e os outros.

A posição hermenêutica é sempre qualitativamente definida e relativamente determinada uma vez que resguarda a proporcionalidade e vínculo originário que se estabelece entre si mesmo e o mundo. Esta posição expressa uma situa-

7 Jeff Malpas apresenta uma discussão muito esclarecedora sobre esse aspecto ao discutir o tipo próprio de espacialidade do mundo, no contexto de Ser e tempo. Ele diferencia aí uma espacialidade objetiva e uma espacialidade existencial, que é fundamental que esteja suficientemente diferenciada para a nossa discussão. Conferir MALPAS, 2008, pp. 67-83. 

contribuições para uma hermenêutica topológica

ção específica, quer dizer, a situação em que existimos, o lugar que habitamos e, portanto, diz respeito à familiaridade e pertencimento. $\mathrm{O}$ habitar e o pertencer a um lugar fornecem orientações ${ }^{8}$ de sentido e de localização que seguimos existencialmente. $\mathrm{O}$ lugar determina nossa posição qualitativa em relação aos entes, a partir da qual nossos comportamentos pré-teóricos e cotidianos, assim como nossas compreensões teóricas sobre os entes, os outros e nós mesmos se torna possível. Desta maneira, a ontologização da compreensão realizada por Heidegger, em Ser e tempo, a partir da hermenêutica da facticidade e toda hermenêutica filosófica de Gadamer e posterior a ele radicalizam a importância de pensar a situabilidade do existir humano, seu ser-no-mundo, e o caráter topológico deste pertencer expresso, inclusive, no termo heideggeriano ser-aí (Dasein). É exatamente por isso que Malpas pode afirmar que: "a hermenêutica é ela mesma essencialmente topológica" (2015b, p. 3). Compreender esta espacialidade em termos hermenêutico-fenomenológicos é decisivo para que possamos pensar o acontecimento de um lugar existencial, que abre as possibilidades de ser quem somos e nos comportarmos interpretativamente em relação ao mundo.

Ao mesmo tempo, Gadamer articula, na passagem citada, os limites de todo horizonte com nossa finitude. A hermenêutica filosófica muito colaborou para a possibilidade de pensarmos radicalmente a nossa situabilidade e finitude. Noções como horizontes de sentido historicamente constituídos e a ideia de mobilidade histórica nos lembram que todo existir humano é sempre situado espacial e temporalmente e, neste sentido, instauram a possibilidade de uma filosofia que realmente pense a existência humana a partir do paradigma da finitude. Mas a maneira como Gadamer dá seguimento à discussão por meio da noção de história efeitual obscurece, de certa forma, a espacialidade em prol da temporalidade. Ao afirmar, por exemplo, que nosso horizonte atual é sempre formado a partir dos horizontes do passado e a maneira como eles se desenvolvem e consolidam por meio da tradição e sua constante reinterpretação, Gadamer recai no que chamamos de primazia da temporalidade e da continuidade histórica em detrimento da espacialidade do acontecimento de um lugar, de uma situação hermenêutica. Assim, a espacialidade do horizonte e da situação hermenêutica, mesmo aqui, são tratadas novamente de forma secundária, enquanto a historicidade e a temporalidade assumem a primazia e centralidade na discussão.

8 Quando Gadamer discute a dialética da pergunta e resposta, ele apresenta a relação entre sentido e orientação: "Sentido quer dizer, todavia, sentido de orientação. O sentido da pergunta é simultâneamente a única direção que a resposta pode adotar se quiser ser adequada, com sentido". (GADAMER, 1999, p. 534). Essa observação, por sua vez, nos permite articular a ideia de horizonte de sentido com a maneira como nos orientamos no interior da delimitação de nossas possibilidades de ver. Se por um lado o conceito de horizonte descreve esta limitação do alcance de nossa visão, o conceito de sentido, aponta para a ideia de que estar situado sempre já depende de orientações prévias vinculantes, que nos permitem ver, compreender e existir em meio aos entes. 
A noção de história efeitual gadameriana se baseia na ideia de que nossas possibilidades interpretativas são diretamente dependentes de compreensões sedimentadas historicamente que, por sua vez, se rearticulam por meio de processos interpretativos. Ainda que tal descrição dos processos compreensivos-interpretativos seja pertinente e esclarecedora, ela parece ser mais apropriada para processos históricos nos quais uma tradição se desenvolve mais ou menos em continuidade (mesmo que marcada por tensões e transformações importantes), como é o caso da tradição ocidental tal qual, supostamente, se realizou em Europa. Mas quando pensamos em uma fusão de horizontes completamente incomensuráveis, ou em processos de subalternização violenta de um horizonte por outro, como no caso dos processos de colonização, novas questões parecem vir à tona. A dificuldade de pensar a fusão de horizontes entre situações hermenêuticas realmente alheias em relação a sua constituição histórica parece reinscrever o problema do acesso hermenêutico que a noção de história efeitual pretendia resolver. Assim, o problema hermenêutico por excelência, a saber, a possibilidade de compreensão do alheio em sua alteridade, se apresenta e impõe uma vez mais.

Neste caso, a grande dificuldade parece ser a constatação de que não existe nenhum ponto de contato histórico entre as diferentes situações hermenêuticas, que se retrairiam em uma alteridade própria, negada pelas hermenêuticas que pensam que essa fusão pode se dar simplesmente de uma forma dialógica entre presente, passado e futuro. As soluções para a tarefa de compreensão de diferentes momentos no interior de uma mesma tradição parecem não serem compatíveis com o problema de compreensão entre lugares totalmente distintos, se aqui entendemos o conceito de lugar hermenêutico-fenomenologicamente. A situação europeia, portanto, possui uma particularidade: seu desenvolvimento se deu supostamente como um processo de continuidade, e neste sentido, é possível compreender a tradição porque sempre já somos compreendidos por ela. Na medida em que a própria sedimentação da tradição é o que abre nossos horizontes compreensivos prévios e suas possibilidades futuras, a tradição já sempre participa da dinâmica de sua constituição mais própria. Entretanto, se desejamos pensar na possibilidade efetiva de acessar a outros lugares, outros horizontes de sentido completamente alheios, sobretudo, daqueles lugares suplantados violentamente, a ideia de história efeitual ou de dialética dialógica parece não ser suficiente para dar conta da questão. 


\section{Lugar, situação e singularidade}

Em um texto recentemente publicado e intitulado Lugar e singularidade (Place and Singularity), Jeff Malpas nos fornece pistas de como pensar o acesso compreensivo a outros lugares entendidos como situações hermenêuticas alheias sem reduzir sua alteridade própria às limitações históricas de nosso próprio horizonte. Ainda que não discuta aí diretamente a questão tal como formulada aqui, Malpas define lugar da seguinte maneira:

Lugar é o que contém, e contendo abre o espaço no qual algo que é dado no interior do lugar pode aparecer - mas este aparecer, o que quer que seja, é um aparecer no interior de [within]. De fato, o self-a própria vida de alguém - é sempre dado em e através de um lugar, daí que o self e a vida também tenham o caráter de um ser (dentro) [within]. (MALPAS, 2015c, p. 77, tradução nossa).

Lugar designa uma totalidade que nos abarca, abrindo o espaço para que as coisas apareçam no interior dessa totalidade. O ser "dentro" aqui não é pensado como encapsulado, como um estar preso dentro de um espaço, tal como um objeto pode estar no interior de um espaço tomado como pura extensão. Ao contrário, ser (estar) dentro aponta para um pertencer, um habitar que instaura certa familiaridade e mantém uma relação originária entre quem habita e seu lugar 9 . Malpas argumenta que esta característica de interioridade implica, ao mesmo tempo, em uma abertura. É justamente a maneira como as coisas e nós somos aí (nos presentificamos), o que define a singularidade própria de cada lugar. Isto é, a maneira específica como se abre o interior no qual nós e as coisas somos, que doa a cada vez a medida da presentação de cada um e da própria relação de si mesmo com os demais é o que caracteriza um lugar como tal. Neste sentido, Malpas afirma: "O singular de cada lugar - o caráter que pertence ao lugar e somente a este lugar - é o caráter de sua abertura e de seu abrir" (Idem, p. 79). O que marca a singularidade de cada lugar, e, por isso, o que define cada lugar enquanto tal é a maneira como os entes se mostram em sua relação essencial com os demais nesta abertura.

9 Heidegger já havia distinguido de forma semelhante a espacialidade do termo ser-em em Ser e tempo (§ 12 ), apesar dele negar o uso da expressão "estar dentro" para descrever o que está em jogo aí, em ambos os casos, tanto para Heidegger, quanto para Malpas essa espacialidade é pensada como vinculação e pertencimento, como um habitar e familiaridade. Contudo, em Ser e tempo, Heidegger afirma que a espacialidade é um aspecto secundário da temporalidade (§70). Para essa discussão conferir Heidegger's Topology: Being, Place, World de Malpas. 
Por esta razão, Malpas sugere que acessar um lugar implica sempre em uma relação essencial com este lugar. Acessar um lugar nunca pode ser pensado como uma simples captura de uma imagem ou a descrição de como se dá a espacialidade objetiva deste lugar. Ao contrário, pressupõe sempre um estar entre, no meio de, no interior desta abertura, o que já quer dizer pertencer e habitar tal lugar: estar existencialmente envolvido e vinculado a esta singularidade. Novamente, é importante reter o caráter fenomenológico dessa noção na medida em que a espacialidade ou a temporalidade de um lugar nunca podem ser tomadas como um pressuposto. Ao contrário, a descrição de um lugar precisa surgir a partir do imiscuir-se em meio aos entes que aí se dão, seguindo a referencialidade própria de tais entes que, desta maneira, trazem à tona a constituição de tal lugar e de sua espacialidade e temporalidade específicas.

De maneira semelhante às discussões que Heidegger realiza na $A$ origem da obra de arte e Gadamer tanto em Verdade e Método como em outros textos $^{10}$, Malpas discute a maneira como poemas ou obras de arte em geral (ainda quando não exclusivamente) possuem a capacidade de nos levar, situar-nos ou re-situar-nos em um lugar. Usando como base um poema de C. K. Stead sobre Kawaika farm, uma localidade na Nova Zelândia, Malpas mostra como o poema serve como uma espécie de "ponto de entrada no lugar" (MALPAS, 2015c, p. 80). Uma vez que: "Estar dentro de um lugar é encontrar-se afetado por esse lugar, orientar-se por seus cursos e direções. No sentido mais amplo possível, é ser capaz de atuar dentro dele, movendo-se através dele." (Idem, p. 79). Um ponto de entrada para um lugar significa, portanto, a possibilidade de aceitar a convocação (no caso do poema) de encontrar morada neste lugar, no sentido de ser capaz de fazer parte dele, respondendo suas referencialidades internas, sendo afetado e orientado pelas medidas que sua abertura instaura. Por isso, uma poesia ou um quadro (ou outras obras) nunca apenas representa uma "imagem" de um lugar, como se fosse possível simplesmente abarcar a abertura de uma totalidade, plasmando um retrato estático do que aí se apresenta. Ao contrário, a obra é sempre um chamado a colocar-se no meio desta abertura, de maneira que possamos nos tornar integrantes da reunião e da totalidade que se apresenta, e, assim, ser capaz de seguir a rede referencial instaurada entre cada coisa que é aí (em um lugar). A obra nos convida a experimentar a singularidade da interioridade da abertura do lugar a que alude, isto é, a maneira como as coisas são presentadas e dispostas aí, em suas mútuas referencialidades, doando uma disposição que orienta nossa relação com tudo o que aí se presenta. Entrar em

10 Para uma discussão e interpretação detalhada destes textos e de sua relação com uma hermenêutica topológica, conferir o artigo já citado: "Place and Hermeneutics: Towards a Topology of Understanding" (MALPAS, 2015b). 
um lugar significa ser capaz de acompanhar as referências dessa abertura, que determinam nosso comprometimento com cada um dos elementos que conquistam seu ser aí e daí também receber nossa própria determinação. Neste sentido, é só quando um autor se situa ele mesmo no interior de um lugar, que ele pode nos "convidar" para entrar aí. A obra traz à tona a abertura do lugar em que o autor habita e pertence, sendo capaz de se mover e ser no interior desta singularidade e, por isso, a obra é capaz de nos convidar a movermos para o interior desta interioridade singular (Idem, 80).

\section{Estranhamento e familiaridade: a obra de arte e o lugar}

Se voltarmos então, ao problema da compreensão de outros lugares, entendida como uma "topologia do ser alheio", nossas considerações prévias sugeriram que uma obra de arte pode funcionar como um ponto de entrada privilegiado para um lugar, sempre que tenhamos em conta que o que está em jogo na obra não é uma imagem ou representação de uma paisagem ou objeto. De fato, nas descrições heideggerianas sobre a obra de arte não é, em absoluto, necessário que o que se presenta na obra seja uma paisagem. Ao contrário, as coisas possuem a capacidade de reunir o mundo, ao requisitar todos os elementos essenciais para a dação de sua medida de ser. A obra de arte precisa, portanto, ser confrontada como aquilo que nos fornece orientações concretas sobre a maneira de habitar um lugar. É necessário se deixar guiar por tal presentação, para que as coisas se mostrem em seu aspecto situado a partir de uma relação autêntica com a totalidade, entendida como reunião de tudo que aí é; que este lugar instaura. Como toda mudança, entrar e habitar outro lugar é um processo de familiarização gradual e um comprometimento existencial com uma espacialidade e temporalidade específicas. Na medida em que o lugar determina os limites de nosso habitar e abre espaço para que as coisas se presentem, compreender é sempre estar atento às orientações e maneira de "ter lugar" específica na interioridade singular de cada lugar. Singularidade esta que, por mais que possa ser negligenciada, sempre resiste e se impõe.

Há ainda um aspecto trabalhado por Malpas no qual vale a pena nos determos. O autor chama a atenção para o fato de como toda compreensão é uma maneira de se situar em relação aos entes e com os outros, que sempre envolve um enredar-se a si mesmo e, assim, conquistar a referencialidade de si em relação aos demais componentes dessa totalidade. Toda compreensão é situada, 

[CP II-R]]

na medida em que é possibilitada pela abertura de medidas que já implica um pertencimento ao lugar e a tudo que aí "tem lugar". O caráter de ser situado, portanto, deve ser pensado como um pertencimento a uma singularidade própria que doa lugar a cada um no interior de uma abertura. $O$ interessante é como Malpas previne que o pertencimento a uma interioridade não pode ser pensado apartado de toda exterioridade. Ele afirma que a interioridade somente ganha seus limites a partir de uma tensão com suas "fronteiras com o exterior", isto é, "através da diferenciação entre lugares e a diferenciação no interior de cada lugar." (MALPAS, 2015c, p. 84).

Mas isso sugere que a interioridade de um lugar, assim como sua singularidade, somente pode ser trazida à tona em uma tensão com certa exterioridade e pluralidade. $\mathrm{O}$ aspecto de contenção e pertencimento que um lugar proporciona não tem nada a ver com um fechamento absoluto, mas, ao contrário, proporciona (e até mesmo insinua) a abertura para outros lugares. É por isso que Malpas pode afirmar que: "Cada lugar é, portanto, um lugar de refúgio e de estabelecimento, um lugar de recinto e de abertura, uma casa e também uma terra estrangeira" (Idem). Neste sentido, toda singularidade expõe e convida à alteridade do outro, na medida em que qualquer identidade só aparece como tal quando confrontada com sua exterioridade, quer dizer, com uma singularidade alheia em sua alteridade própria.

Essas considerações parecem ser decisivas para pensarmos o aspecto fundamental de uma hermenêutica topológica como atenção a essa dinâmica de dação do lugar. Elas também aproximam a obra da maturidade de Heidegger e sua topologia do ser da proposta que esta sendo apresentada aqui de uma topologia hermenêutica. E isso porque nesses textos nos quais a quaternidade ${ }^{11}$ surge, Heidegger sugere que mostração de uma coisa depende de sua relação com todas as demais que compõe a totalidade a qual se pertence e que doa a medida de um mundo, enquanto lugar de reunião. Essa discussão ajuda também a compreender porque as obras de arte podem ser "coisas" privilegiadas que servem como "pontos de entrada" para os lugares hermenêutico-fenomenológicos. É justamente na medida em que existir significa sempre já estar situado em um lugar, que o próprio acontecimento desse lugar se retrai em detrimento das coisas que aí são e se presentam. Quer dizer, para que possamos contar com a familiaridade do mundo (uma totalidade referencial enquanto lugar hermenêutico-fenomenológico) que se insinua em cada coisa, cada coisa já precisa aparecer a partir da positividade de seu ser conquistado no interior desta reunião.

11 Dado o limite e escopo do trabalho, não podemos discutir especificamente as mudanças que ocorrem no pensamento heideggeriano tardio, nem mesmo nos deter na apresentação de seus conceitos fundamentais. Para essa discussão, ver meu texto: Verdade, finitude e lugar, 2016 (referências completas na bibliografia). 
Daí Heidegger afirmar em A Origem da Obra de Arte, quando analisa um quadro de Van Gogh (um par de sapatos - segundo Heidegger supostamente pertencentes a uma camponesa), que a camponesa provavelmente só sabe da relação e da medida que seus sapatos estabelecem com seu mundo, ao calçar os sapatos. Isto quer dizer que a relação entre uma coisa e seu lugar, enquanto uma totalidade que fornece a medida de nosso habitar este lugar e uso das coisas, só se revela para a camponesa em meio a sua dinâmica existencial cotidiana. Em outras palavras, na medida em que a camponesa calça os sapatos e anda e se relaciona com as coisas de uma determinada maneira, ela já se comporta de acordo e a partir da familiaridade com o seu mundo.

Contudo, no momento em que Van Gohn pinta os sapatos, o par de calçados aparece como uma obra de arte, capaz de destacar a 'coisa' de sua imersão imediata nesta rede de mútuas determinações. Isso significa que através do quadro somos capazes de ver, pela primeira vez, a coisa como coisa, isto é, de ver o sapato enquanto tal, a partir dele, sua relação com o lugar a que ele pertence - ao invés de simplesmente usar os sapatos em sua familiaridade cotidiana e imediata. Este processo de destaque da coisa se realiza por meio de um deslocamento, no sentido de "tirar do lugar" original. É porque o sapato não está nos pés da camponesa, mas, ao contrário, está aí, frente a nós, presente no quadro, que conseguimos vê-lo enquanto tal e nos tornamos capazes de estranhá-lo pela primeira vez a ponto de nos disponibilizarmos a seguir suas indicações, que fornecem, assim, um ponto de entrada para o mundo (o lugar) da camponesa. A obra de arte desloca a coisa de seu lugar e, por isso mesmo, permite que sejamos capazes de ver como cada coisa requisita um lugar próprio.

Para sermos capazes de acessar o lugar como lugar, isto é, para sermos capazes de nos remeter para dentro de sua interioridade plenamente, precisamos, antes, de um deslocamento, de um estranhamento que nos faça experimentar a alteridade e singularidade desse lugar, e, assim, problematizá-lo enquanto tal. A imersão na familiaridade de um mundo obscurece essa experiência topológica. É preciso experimentar certa estrangeiridade para ver o lugar enquanto tal. Por isso, Heidegger também afirma que, quando se pensa na ponte de Heidelberg, se pode estar mais próximo dela do que quem a atravessa todos os dias, na medida em que a familiaridade de uso cotidiano suprime completamente a distância em relação à ponte, não permitindo, portanto, o aproximar-se dela.

Isso significa que é necessária uma experiência fundamental de estranhamento e alteridade para que sejamos capazes de nos aproximar das coisas de um mundo, de tal maneira que elas possam fornecer um "ponto de entrada" para seu 
lugar. Essa experiência também pode ser dada por uma estrangeiridade própria vindoura de outra experiência que não a obra de arte, como a confrontação com compreensões radicalmente alheias ou pela alteridade que se insinua em experiências limites que colocam em jogo nosso próprio horizonte sedimentado.

A tarefa de uma topologia hermenêutica, então, é resguardar esse espaço de estranhamento que se realiza como uma volta à vinculação, uma volta ao lugar a que se pertence, para que o limite - a própria medida (e desmedida) deste lugar - possa se tornar questionável. As maneiras possíveis de se voltar a atenção para nosso próprio lugar são diversas e podemos, certamente, encontrar muitos caminhos para o pensamento. Mas, como vimos, a obra de arte e a confrontação com o lugar alheio parecem se mostrar como pontos de entrada privilegiados, na medida em que produzem um estranhamento e distanciamento da coisa para que possamos, pela primeira vez, vê-la enquanto tal e, desta forma, trazê-la para próximo de nós, em sua medida de mostração e em sua convocação para nosso pertencimento ao habitar o lugar próprio em meio ao qual se dá o aparecimento das coisas e a realização de nossa exist ência.

\section{Considerações Finais}

Por tudo o que foi apresentado até aqui, esse texto propõe e defende a necessidade de pensarmos uma hermenêutica topológica. Defende-se aqui a manutenção do termo hermenêutica na medida em que, no exercício de voltar a atenção ao nosso lugar, articulamos mais uma vez estranhamento e familiaridade (e, desta forma, identidade, alteridade e singularidade) nos processos interpretativos. Esses elementos e a questão sobre como compreender o alheio em sua alteridade e em relação com nosso próprio horizonte sempre mobilizaram os esforços da tradição hermenêutica. Além disso, a ideia de uma topologia, tal como foi apresentada aqui, aponta para um copertencimento que instaura uma unidade de requisições mútuas equiprimordiais e, neste sentido, resgata outra versão da noção de círculo hermenêutico entre o todo e suas partes. Em outras palavras, temos aqui, novamente, a instauração de um círculo hermenêutico, dado que o termo lugar nomeia a abertura de determinada totalidade a qual pertencemos e a partir da qual as coisas aparecem enquanto tal e que o ser dessas coisas depende de sua relação com essa totalidade, ao mesmo tempo em que essa totalidade é conformada pela relação de cada parte que a compõe. 
Finalmente, tal pensamento reivindica colaborar com a pesquisa hermenêutica, uma vez que toda compreensão e interpretação se mostram como 'estar junto de' e 'em meio a', e se realizam existencialmente como este estar situado e pertencer a um lugar que nos torna capazes de seguir determinada referencialidade, que sempre já nos inclui, nos abarca e possibilita - quer tratemos da interpretação de um texto, de nossos comportamentos cotidianos ou da presentificação dos entes no mundo. Desta maneira, recuperar os aspectos espaciais da hermenêutica abre o caminho para desenvolvermos uma hermenêutica topológica que muito pode contribuir para avançarmos no pensamento das questões que perpassam toda a tradição hermenêutica, ao mesmo tempo em que pode nos ajudar a revelar e superar alguns vícios eurocentrados e colonialistas dessa tradição.

Recebido em: 31.08 .2017 | Aprovado em: 19.09.2017

DILTHEY, W. A construção do mundo histórico nas ciências humanas. Trad. Marco Antonio Casanova. São Paulo: Editora UNESP, 2010.

.Dos escritos sobre hermenéutica: El surgimiento de la hermenéutica y los Esbozos para una crítica de la razón histórica. Trad. ao espanhol: Antonio Ramos. Madrid: Ediciones Istmo, 2000.

FIGAL, Günter. Oposicionalidade: $O$ elemento hermenêutico e a filosofia. Tradução de Marco Antonio Casanova. Petrópolis: Editora Vozes, 2007.

FURTADO DE MELO, Rebeca. "Entre compreensão e interpretação: para uma hermenêutica filosófica no pensamento de Heidegger". In: Ekstasis: Revista de Hermenêutica e Fenomenologia. Rio de Janeiro, vol.2, n.1, pp. 84-99, 2013.

FURTADO DE MELO, Rebeca. Verdade, finitude e lugar: para uma hermenêutica topológica. 2016. $350 \mathrm{f}$. Tese (Doutorado em Filosofia). Universidade do Estado do Rio de Janeiro, Rio de Janeiro, 2016.

GADAMER, Hans-Georg. Heidegger's way. Traduzido ao inglês por John Stanley. Albany: State University of New York Press, 1994.

Verdade e Método: traços fundamentais de uma hermênutica filosófica. (3 ed). Tradução: Flávio Meuer. Petrópolis: Editora Vozes, 1999.

Verdad y método: fundamentos de una hermenéutica filosófica. Tradução para o espanhol de Ana Agud Aparicio e Rafael de Apagito. Salamanca: Ediciones Sígueme, 1984.

.Philosophical Hermeneutics. Tradução para o inglês de David E. Linge. California: University of California Press, 1977.

GRONDIN, Jean. Introducción a la hermenéutica filosófica. Trad. para o espanhol: Angela Ackermann Pilári. Barcelona: Herder, 2002. 
HEIDEGGER, Martin. Ontologia (Hermenêutica da facticidade). Trad. Renato Kirchner. Petrópolis: Editora Vozes, 2012.

Bremen and Freiburg Lectures: Insight Into That Which Is and Basic Principles of Thinking. Tradução para o inglês de Andrew Mitchell. Bloomington \& Indianapolis: Indiana University Press, 2012.

.A Origem da Obra de Arte. Tradução:

Laura de Borba Moosburger. 2007. 149f. Dissertação (Mestrado em Filosofia). Universidade Federal do Paraná: Curitiba, 2007.

Ser e tempo. Parte I e parte II. Trad. Marcia Cavalcante Schuback. Petrópolis: Editora Vozes, 2005.

MALPAS, Jeff. O aceno da linguagem: A transformação hermenêutica do pensamento de Heidegger. Tradução de Alexander de Carvalho. In: Revista Ekstasis, Vol. 1 - n. 1, 2012.

.Heidegger's Topology: Being, Place, World. Cambridge: The MIT Press, 2008.

.(2015a) "Introduction: Hermeneutics and Philosophy". In: The Routledge Companion to Hermeneutics, Oxon e New York: Routledge, 2015, pp. 1-9.

.(2015b). "Place and Hermeneutics: Towards a Topology of Understanding". Forthcoming in Georgia Warnke (ed.), Inheriting Gadamer: New Directions in Philosophical Hermeneutics. Edinburgh: Edinburgh University Press. Disponível em: https://www.academia. edu/12073967/Place_and_Hermeneutics_Towards_a_Topology_ of_Understanding. Acessado em: 20/05/2015.

.(2015c) "Place and Singularity" In: MALPAS (ed.). The Intelligence of Place: Topographies and Poetics. London: Bloomsbury, 2015, pp. 67-92.
MALPAS, GANDER (eds). The Routledge Companion to Hermeneutics, Oxon e New York: Routledge, 2015, pp. 354-367.

MENESES, Maria Paula. Epistemologías del Sur: diálogos que crean espacios para un encuentro de las historias. In: VIANELLO; MAÑ́ (org.). FormasOtras: Saber, nombrar, narrar, hacer. Barcelona: CIDOP, 2011, pp. 31-42.

.Os sentidos da descolonização: uma análise a partir de Moçambique. In: OPSIS (Online) Catalão, v. 16, n. 1, jan./jun., 2016, pp. 26-44.

SIKKA, Sonia. "Heidegger and Race". In: BERNASCONI e COOK (eds). Race and Racism in Continental Philosophy, Bloomington \& Indianapolis: Indiana University Press, 2003, pp 74-97.

.(2015d) "Place and Situation". In:

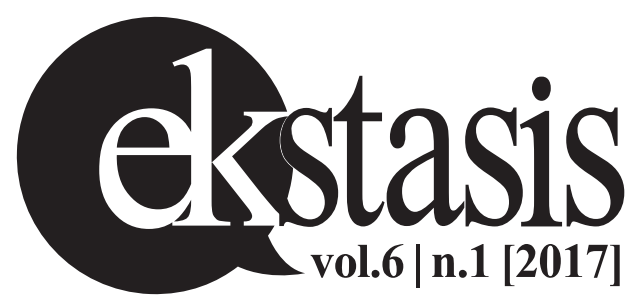

